\title{
BACHIANAS BRASILEIRAS JA KANSALLISEN NEOKLASSISMIN ONGELMA
}

Villa-Lobos • Bachianas brasileiras - nationalismi • banaalisuus sensuaalisuus primitivismi - triviaalimusiikki - kitsch - aika - historiallisuus - estetiikka • iberinen ihminen $\cdot$ capadocio $\bullet$ improvisaattori $\bullet$ intonaatio

\section{Taustaa}

Heitor Villa-Lobosin (1887-1959) elämässă selvän vedenjakajan muodostaa 20- ja 30-lukujen vaihde. Se merkitsee vaellusvuosien loppumista, mutta samalla myös Villa-Lobosin lähtöă Euroopasta hetkenä, jolloin hänellä alkoi olla, erityisesti sen eteläisissä osissa, nimeä huomattavana kansallisena säveltäjänä. Myös VillaLobosin tuotannossa paluu kotimaahan pidemmäksi aikaa muodostaa eräänlaisen murroksen. Jos verrataan hänen 30-lukunsa pääteosta Bachianasin sarjaa 20-luvun "symboliksi" kohoavaan Choros-sarjaan, tyylillinen ja sisällöllinen ero on melkoinen. Tästä huolimatta Juan Orrego Salas toteaa Villa-Lobos-esseessään: "Kuitenkaan tällainen kytkentä ei muodosta kylliksi karakteristista aksenttia, jotta voisimme katsoa Bachianasien eroavan olennaisesti Villa-Lobosin muista teoksista." (Orrego-Salas 1966, 29). Tietenkin on selvää, että niin Chorokset kuin Bachianasit ilmentävät kansallista tyyliä, mutta siinä missä Chorokset edustavat "brasilialaisuutta" kansainvälisessä avantgarde-asussa, siinä Bachianasit heijastavat kansallisuutta huomattavasti helppotajuisemmassa ja sovinnaisemmassa muodossa.

Villa-Lobosin "kansainvälistä kansallisuutta" vieroksuttiin hänen kotimaassaan syistä, jotka brasilialainen musiikkitieteilijä Helza Cameu osuvasti kuvaa:

Näiden teosten (Chorosten) analyysi saattaa meidät havaitsemaan tiettyjä vapauksia, jotka säveltäjä omaksuu muodon suhteen - ne saattavat ensinäkemältä vaikuttaa välttämättömien teknisten taitojen puuttumiselta... Mutta tähän tulokseen päädytään ainoastaan mikäli ymmärrämme muodon sen akateemiselta kannalta emmekä spontaanin luomisen logiikan tuloksena. (Cameu i.v., 6). 
Mutta kun Villa-Lobos sitten noudatti "akateemisten" kriitikkojensa toivomuksia ja palasi "Bachiin" sekä äärimmäisen yksinkertaisiin, klassisiin muotorakenteisiin, hän joutui puolestaan eurooppalaisten kriitikkojensa arvostelun kohteeksi eli Claude Samuelin suulla ilmaistuna:

Lyhyesti sanottuna, Villa-Lobosilta löytyy sekä parasta että kehnointa. Paras on peräisin intiaanien tai brasilialaisten folkloresta, jolla on meille alkuperäinen ja houkutteleva tuoksunsa; parasta on myös tämän muusikon runsauden henki ja tietty soittimellinen rikkaus. Mutta kehnoimman aineksen löydämme helposti hänen omaksumassaan 'klassisessa' perinnössä. (Samuel 1962, 81-82).

Näin ollen Bachianasien estetiikka edustaa täysin erilaista musiikillista asennoitumista kuin Choroksien kauden fauvismi. Bachianasien juuret ovat ehkä vielä syvemmin Brasiliassa kuin Choroksien, emmekă voi ymmărtăă niiden banaalisuutta ja sensuaalisuutta tuntematta brasilialaisuutta. Vaikka ne edustavat suorastaan liioiteltua, ylikuumennettua nationalismia, kuten Villa-Lobosin muutkin musiikilliset pyrkimykset tuona koko Brasilian kriisikautena, niistä parhaimmissa tapahtuu yllättävä kohoaminen universaalisuuteen ja tiettyyn suuruuteen, jota ilman kansanmusiikista ei voi kehkeytyä suurta taidemusiikkia. Se mitä Arnold Schönberg sanoi Beethovenin jousikvartetosta sopii myös Villa-Lobosiin:

Kansantanssina théme russe on varmasti hyvin miellyttävä. Mutta se että nyt on olemassa venäläistä musiikkia on varmasti joidenkin suurten säveltäjien ansiota. Jollei näin olisi, suuria irlantilaisia ja skotlantilaisia sinfonioita pitäisi jo olla sävelletty, koska niiden kansojen folklore on ylivomaisen kaunista ja täynnä vaikuttavia ja karakteristisia piirteitä... (Schönberg 1975, 162).

Joka tapauksessa Bachianaseissa Villa-Lobos astuu hetkeksi eurooppalaisen musiikinhistorian kiihkeän muutosprosessin ulkopuolelle. Noissa loputtoman hitaissa "maan lauluissa" ja "aarioissa" hän on eräăssă mielessä yhtä maansa äärettömien mittasuhteiden, erämaiden ajattomuuden kanssa. Niistä häntä ei erota vaan päin vastoin niihin häntä yhdistää Bach, säveltäjän omalaatuisen tulkinnan mukaan "kaikkien kansojen musiikin universaalin lähde".

Bachianaseissa Villa-Lobos palaa Brasilian "aikaan", joka Euroopan kannalta koetaan ehkä "ajattomuutena", arkaaisuutena, lévi-straussilaisena "kylmän yhteiskunnan hitautena". Brasilialainen sosiologi Gilberto Freire - joka ei kuitenkaan pidä itseään sosiologina vaan kirjailijana - on pohtinut brasilialaisen ihmisen suhdetta aikaan ja todennut, etteivät portugalilaiset tuoneet kelloja mukanaan uuteen maailmaan.

Se seikka että iberinen kulttuuri jää suuressa määrin sivilisaatioksi, jonka ihmisen perusasennetta aikaan hallitsevat myytti, uskonto ja folklore sen sijaan että sitä ohjaisi ... tieteellinen näkemys tai käsitys jatkuvasta toiminnasta historiallisena edistyksenä, näyttää asettavan iberisen ihmisen ja 
sivilisaation ainutlaatuisen asemaan. Iberinen ihminen on kehittänyt hitaan rytmin, jota edistykselliset eurooppalaiset ja angloamerikkalaiset pitävät luovana ja arkaaisena - yksinkertaisesti ja tieteellisesti edistyvän 'rytmin' sijasta. Luovana siinä mielessä että useimmat tyypillisesti iberiset ja espanjalaiset ihmiset ovat kykeneviä - samoin kuin orientaaliset ja primitiiviset ihmiset - nykyhetkessä 'alkamaan kaiken uudestaan', löytämään 'puhtaan' olemassaolon koskemattomine mahdollisuuksineen. ... He samaistuvat aikaan, joka 'alkaa joka vuosi uudestaan'; näin he välttävät historian sanan ankarassa mielessä ja pakenevat loogista syy-seuraus -suhdetta. Heidän olemisensa on ennemmin olemassaoloa kuin historiaa, heidän aikansa ennemmin kvalitatiivista elämää kuin sarja loogisia ja kvantitatiivisesti mitattavia toimintoja. (Freire 1972, 143).

Sikäli kuin musiikki on kulttuurinsa heijastaja tai "maansa kukka" käyttääksemme Jean-Aubryn osuvaa ilmausta, Freiren kuvaus sopii hyvin VillaLobosin Bachianasien, hänen brasilialaisista brasilialaisimman sarjansa taustaksi. Mikään ei ole sille vieraampaa kuin schönbergiläinen developing variation, joka on tyypillisesti eurooppalainen keksintő, historiallisuuden idean transponointi musiikin alueelle ja jonka esimerkillisimmät toteuttajat Haydn, Mozart ja Beethoven elivät juuri kautena, jolloin eurooppalainen ihminen tuli tietoiseksi omasta historiallisuudestaan. Schönberg sanoo, ettei hän muista ainuttakaan säveltäjää, joka olisi em. metodilla johtanut uusia musiikillisia ideoita kansanlauluista. Jos kohdistamme Schönbergin arvion Villa-Lobosiin, saamme esiin tilanteen, jossa eurooppalainen ihminen arvostelisi iberisen ihmisen pohjimmiltaan täysin erilaista käsitystä, ei vain siitä mitä nimitämme musiikin estetiikaksi, vaan itse musiikin perustavasta elementistä, ajasta:

Yleensä ottaen tarvitaan jokin metodi tekemään lyhyestä tarinasta pitkä: lukuisia lyhyen fraasin kertauksia ... transponointeja muihin sävellajeihin, soitinnuksen muutoksia, ja nyttemmin dissonoivien harmonioiden lisäyksiä sekä sitä mitä Hollywood-sovittajat kutsuvat kontrapunktiksi ts. toisistaan riippumattomien äänten 'pyyteettömiksi lahjoiksi'. Siten mitään ei sanottu, mitä ei jo sanottu sävelmän ensiesiintymisessä. (Schönberg 1975, 164-165).

Villa-Lobosin Bachianasien teemat ovat usein itseään heijastelevia, suorastaan narsistisia - mutta parhaimmassa tapauksessa omaan suuruuteensa kohoavia. Niiltä ei voi vaatia sellaista, mihin niitä ei ole tarkoitettukaan. Ei Schönbergkäăn kiistänyt kansanmusiikin arvoa sinänsä, sillä "luonnollinen kansanmusiikki on aina täydellistä, koska se syntyy improvisaatiosta ts. innoituksen välähtävästă salamasta" (ibid. 163). Juuri tämä kvaliteetti Villa-Lobosilla, kansanmusiikin hengen ruumiillistumalla kiistatta parhaina hetkinä on.

Niin kuin Freire kuvaa iberistä ihmistä, joka on aina valmis alkamaan alusta, samoin Villa-Lobos palaa Bachianasien kaudessa siihen, mitä hän pitäă musiikin alkulähteenä. Hän luopuu dissonoivasta, vääristyneestä, protestoivasta tyylistään ja siirtyy äärimmäiseen yksinkertaisuuteen. Kuten jo Villa-Lobosin varhaiskautena hänen tuotantonsa lankeaa satunnaisesti yhteen esim. Stravinskyn ja Prokofjevin skyyttiläisyyden kanssa, samoin tätä kautta voi pitää hänen 
neoklassisminaan - vastaavana ilmiönä kuin mitä Shostakovitshin tuotannossa edustavat 24 preludia ja fuugaa, Chavezilla 12 preludia, Ravelilla Tombeau ja Sibeliuksella VI sinfonia - eli paluuna musiikin vanhempiin kerrostumiin.

Tosin Villa-Lobosin "yksinkertaisuudella" on myös aivan määrätyt kulttuurihistorialliset syynsä. Villa-Lobosin tuotanto kokonaisuudessaan heijastaa Brasilian kulttuurin murrosta - muutosta agraarisesta yhteiskunnasta teollisen vaiheen urbanisoituneeseen sivilisaatioon. Choroksien musiikissa vielä elää puutarhojen ja serenadien pohjimmiltaan melko maalainen Rio - hänen myöhemmässä tuotannossaan voimme jo kuvitella kosmopoliittisen betoni-Rion, mikä ilmenee säveltäjän kielen irtaantumisena välittömästă folkloresta, keskittymisenä puhtaammin rakenteelliseen mielikuvitukseen, joka luo korkeintaan nostalgisia katseita kadonneeseen nuoruuteen. Näiden kahden kauden väliin sijoittuu säveltäjän elämän 30-luku, massojen musiikkikasvatus, kiihkeä musiikillinen nationalismi ja Bachianas brasileiras.

\section{Banaalisuuden estetiikka}

Toisen Bachianasin ensimmäinen osa antaa erityisesti aiheen pohtia VillaLobosin "neoklassisen" tyylin asemaa ja sen suhdetta vastaaviin ilmiöihin Euroopassa, samoin kuin musiikillisesti "banaalin", jopa musiikillisen kitschin ongelmakenttää. Tämän Bachianasin osilla ei ole sinänsä muuta yhdistävää tekijää kuin orkestrointi, jossa esiintyy runsaasti eksoottisia brasilialaisia lyömäsoittimia: ganza, chocalhos, matraca, reco-reco ja caixa. Erityisesti huomiota kiinnittää saksofonin hallitsevuus ensimmäisessä osassa. Ensi osa tuo esiin myös brasilialaisuudesta piirteitä, joita voisi helposti kuvata termeillä "sentimentaalinen", "tyhjä paatos", "mauton", "triviaali", "epäaito" ja "teennäinen", toisin sanoen adjektiiveilla, joilla tavallisesti juuri kuvataan kitschiä. Mm. saksalaiset musiikkitieteilijät ovat tutkineet musiikillisen kitschin ongelmaa, kuten Tibor Kneif, joka määrittelee sen ihmisen triviaalin tietoisuuden tulokseksi, erityiseksi adornolaiseksi kuulijatyypiksi. Monet triviaalimusiikin piirteet johtuvat triviaalin tietoisuuden pyrkimyksestä karttaa todellisuuden kovuutta (ehkä erityisesti brasilialainen piirre, tärkeä ominaisuus maassa, jossa ei milloinkaan sanota "ei", vaan kaikki silotellaan "kyllän" eri vivahteiksi). Tällöin myös musiikin heijastama todellisuuskuva saattaa jäädä klisheemäiseksi. Saattaisi ajatella, että Tibor Kneifin triviaalisuuden määritelmää voisi soveltaa eräisiin brasilialaisiin mesomusiikin tapauksiin: "Triviaalisuus syntyy kun romanttinen, antiteeseiksi jännitetty ja äärimmäisyyksissä liikkuva ajatus- ja tunnemaailma joutuu epäinnoittuneiden jäljittelijöiden käsiin ..." (Kneif 1967, 37).

Se, miten Kneif kuvaa kaipuuta menneisyyteen triviaalimusiikin perustunnelmana, voisi jonkun mielestä sopia Villa-Lobosiin:

Kaipuu takaisin terveeseen maailmaan ilmenee soivassa hahmossa. Sen tuo mieleen sujuva, toissapäiväinen melodinen varasto ja sekä yleisesti hyväksytty soinnullinen varustus. Vanha, aikansa elänyt tyylivarasto modernisoidaan vain sikäli kuin säveltäjä silottelee sen ulkoisilla ja satunnaisilla erikoisuuksilla, 
jotka ovat peräisin nuoremmasta tyylikehityksestä. --- Tällä tavoin saavutettu kiilto paljastaa, ettă tällaista musiikkia on tuotettu sarjamaisesti ja saman reseptin mukaan nopeasti. Itse teoksen ristiriita syntyy siitä, että haaveiltu kuva vanhasta yksinkertaisuudesta ja turvallisuudesta tuottaa aina heikkoja kohtia, puutteita: muodon suljettu luonne ja samalla arkaisoiva havainnollisuus särkyy tai katkeaa siihen sovitettujen elottomien tunnelmien johdosta, jotka ovat tuttuja vain nykyaikaiselle anonyymille kaupunkilaiselle. (ibid. 38-39).

Jos ylipäätään suunnataan neoklassismiin tämä kritiikki, jonka Kneif on kylläkin tarkoittanut ns. viihdemusiikkia ts. varsinaista triviaalimusiikkia koskevaksi, päädytään oikeastaan samaan lopputulokseen kuin Adorno Stravinsky-kritiikissään. Voisi hyvin kuvitella, ettă Adorno olisi kirjoittanut saman VillaLobosista kuin Stravinskystakin, jonka primitivistinen kausi oli hänen mielestään infantiilin sielunelämän heijastusta: stravinskylainen regressio korvaa toisaalla temaattisen kehittelyn - länsimaisen musiikin sinfonisen ajattelun periaatteen, jota Asafjev nimitti "sinfonismiksi" ymmärtäen sillä kuitenkin laajempaa aluetta kuin Adorno. Näin Stravinsky tekee musiikin epäkäsitteellisestä kielestä esi-Minä alueen orgaanin. "Hän konstruoi kuvitteellisen kansatieteellisen mallin esi-individuaalisesta ...", mistä Adornon mukaan seuraa Stravinskyn tuskin spesifisti musiikillinen, vaan ennemmin "antropologisesti selitettävä vaikutus". (Adorno 1958, 157). Stravinskyn neoklassisen kauden teokset ovat hänen mielestäăn von überaus schwankenden Niveau (läpeensä häilyvää tasoa). $\mathrm{Ne}$ ovat hänen mielestään unorganisch, sillä ne perustuvat esiklassisten sekvenssikaavojen katkelmallisiin malleihin. Puolestaan Stravinskyn myöhäis-kautta hän ilkeästi luonnehtii termillä etwas kunstgewerblich Mattes (jotain taideteollisen latteata) (ibid. 194). Ennen kaikkea Adorno tuomitsee neoklas-sismin tietyn hilpeyden, Heiterkeitin, koska hänen mielestään siihen ei tuona kautena, 20- ja 30-luvuilla, ollut objektiivisesti ottaen mitään aihetta.

Näin Adorno osoittaa oman lähtökohtansa olevan puhtaasti yhteiskunnallisfilosofisessa ajattelussa, joka puolestaan liittyi tuon ajan saksalaisen yhteiskunnan tilanteeseen. Mikä on Adornon teorian ja lähestymistavan arvo ja validiteetti saksalaisen kontekstin ulkopuolella, voidaan täysin aiheellisesti kysyä ja tarkastella samalla myös eräiden myöhempien saksalaisten musiikkikriitikkojen varsin negatiivisia käsityksiä sellaisista säveltäjistä kuin Sibelius, Villa-Lobos tai Ives. Kahta ensinmainittua ei edes mainita Heinrich Stuckenschmidtin teoksessa maailmansotien välisen ajan musiikista. Muistelmissaan hän silti kuvaa Villa-Lobosia sanoilla:

Hänen suunnaton luomisvoimansa tuotti elämäntyön, joka ulottui lapsellisesta banaliteetista ja kauhistuttavasta epätaiteellisuudesta muodon ja ilmaisun korkeuksiin. --- Jotkut hänen Choroksistaan ja Bachin polyfonian hyvin omintakeisesta tulkinnasta syntyneistä Bachianas brasileiraksistaan antavat aavistaa suuren neron, jossa sekoittui eurooppalainen ja intiaaniveri. --Stravinskya hän tuntui arvostavan vain vähän ja Schönbergiin hän asennoitui kunnioittavalla ymmärtämättömyydellä. Hänen mielipiteensä estottomuudessa vaistosin sukulaisuutta Vareseen. (Stuckenschmidt 1976, 142). 
Carl Dahlhaus puolestaan vaatii, ettă triviaalimusiikki on voitava määritellă itse musiikillisen tekstin ominaisuutena: "Esteettiset arvioinnit ovat kestämättömiä, jollei niită tueta sävellysteknisillä analyyseillă. On voitava osoittaa nuottitekstistä, miten yksinkertainen eroaa triviaalista, tunne sentimen-taalisuudesta, ilmaisullisesti kaunis kitschistä." (Dahlhaus 1967, 24).

Esimerkkinä tästä Dahlhaus analysoi Tshaikovskin viidennen sinfonian Andante cantabilea. Sen pääaiheen tonaalinen rakenne on äärimmäisen yksinkertainen, mutta sen, että Tshaikovski saa yksinkertaisen dominanttiseptimisoinnun purkauksen toonikaan näyttämään tärkeältä tapahtumalta aksentoiduilla pidätysäänillä, Dahlhaus tulkitsee yritykseksi muuttaa yksinkertainen banaaliksi, antaa musiikille enemmän merkitystä kuin sillă itsessäăn on. Joku toinen analyytikko näkisi asian täsmälleen päinvastaisessa valaistuksessa ja sanoisi Tshaikovskin käyttävän taitavaa vieraannuttamisefektiä, jossa musiikillisen arkitietoisuuden automatisoitunut struktuuri - dominantti-toonika-suhde saadaan näyttämään kuin uudelta keksinnöltä, joka tapauksessa merkittävältä musiikilliselta tapahtumalta. On hyvin luultavaa, ettei trivi-aalisuutta, banaalisuutta ja kitschmäisyyttä voida milloinkaan määritellä kuin tietyssä kontekstissa, suhteessa tiettyyn musiikilliseen maailmankuvaan. Tässä mielessä Kneifin lähestymistapa tuntuu oikeutetummalta: mitä hienoinkin musiikki muuttuu triviaaliksi, kun se astetaan palvelemaan banaalia funktiota. Jopa Dahlhauskin myöntää, että "banaali" on musiikillisesti lähes analysoimaton kategoria. Se mitä hän tässä yhteydessä sanoo, voitaisiin hyvin kuvitella eräänlaiseksi "hypoteettiseksi" kritiikiksi Villa-Lobosia kohtaan:

Kukaan ei kiistä, etteikö potpurin periaate, muodoksi kohotettu muodottomuus muodostaisi banaliteettia. Arvioinnin varmuus muuttuu kuitenkin neuvottomuudeksi, kun on näytettävä musiikillisin tunnusmerkein, miten mielekäs kontrastointi eroaa tyhjäksi suhteettomuudesta eli juuri potpurimaisuudesta. Heterogeenisyyden todistaminen on vaikeampaa kuin paljastaa yhteyksiä. (ibid.).

Jos tarkastellaan Bachianas brasileiras nro 2:n ensimmäisen osan pääteemaa näiltä kannoilta (esimerkki 1), niin huomataan, miten vaikeaksi käy todistaa VillaLobos banaaliksi säveltäjäksi - huolimatta siitä ensi kuulemalta useimmat banaalisuuden ja triviaalisuuden välttämättömistä ehdoista ovat luettavissa itse musiikillisesta rakenteesta. Adhemar Nobregan kommentti, ettei kyseessä ole oikeastaan teema, koska "teemaksi" katsottava temaattinen yksikkö, lauseke on 20 tahtia pitkä, ei sinänsä pidä paikkaansa - onhan Sibeliuksenkin 7. sinfonian ensiosan pääteema jättiläispitkä, samoin Mahlerin 5. sinfonian kuuluisa adagioteema. Länsimainen kuulija vaistomaisesti kuulee kuitenkin Villa-Lobosin "teeman" intonaatioiden olevan peräisin toisesta maailmasta kuin se henkistynyt ideaalisuus joka luonnehtii Sibeliuksen ja Mahlerin em. teemoja. Hän voisi jopa löytää teoksesta seuraavia banaaleiksi pääteltäviä intonaatioita:

1) Sointiväri: saksofoni, jolle lienee länsimaisessa taidemusiikin traditiossa tarjottu vain harvoja esteettisesti täysin hyväksyttäviä käyttöjä sinfoniaorkesterin 

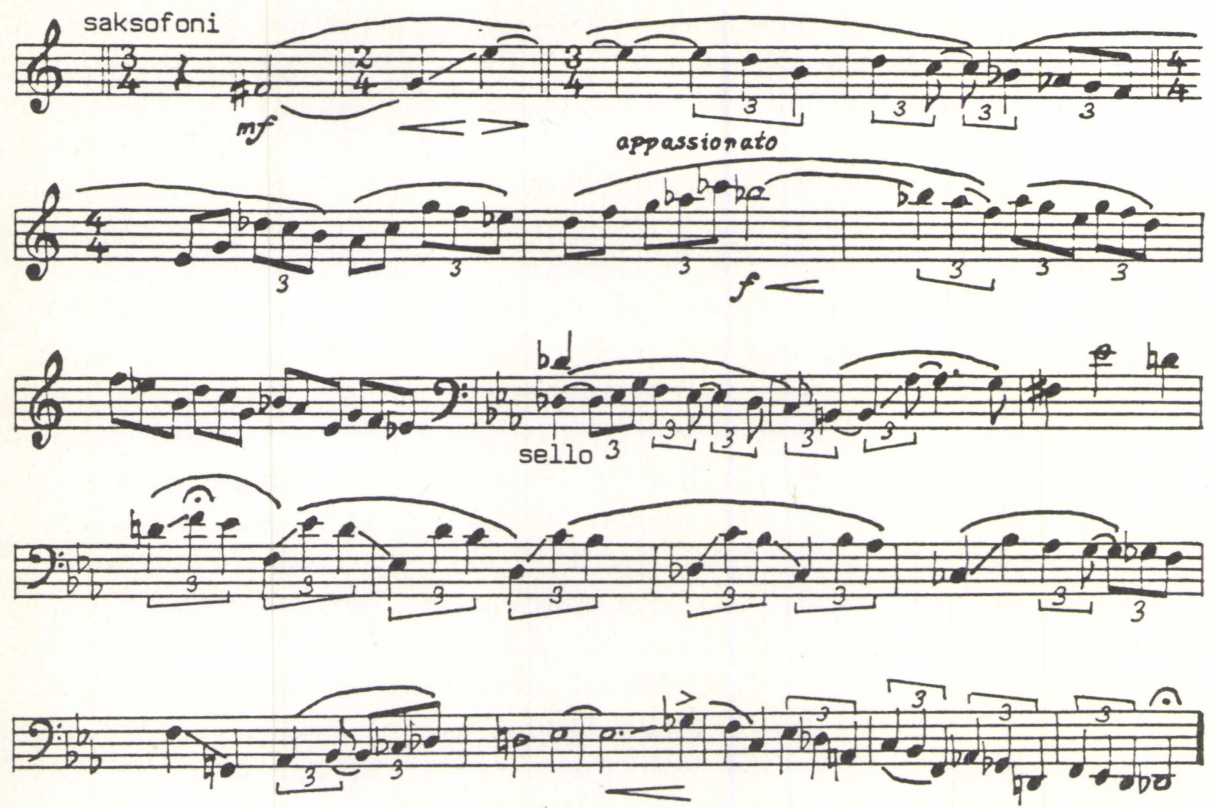

sointikuvassa (suuressa määrin juuri saksofonin sointivärin johdosta teemaa luonnehtii länsimaisen sinfonisuuden edellyttämän sublimaation asemesta paljas ja avoin sensuaalisuus);

2) teema tuntuu rakenteeltaan yksinkertaiselta, koska se koostuu loputtomista sekvenssisarjoista, jotka näyttävät liittyvän toisiinsa potpurimaisesti ja heterogeenisesti. Mutta kun lähemmin tarkastelee tätä teemaa niin huomaa, että redundanssi on suuressa määrin näennäistä: itse asiassa vasta teeman loppupuolella se tuntuu urautuvan tiettyihin toistuviin neljäsosatriolikaavoihin. Alussa sekvenssien hahmo säilyy vain pääpiirteissään, sillä tietyissä rajoissa intervallit vaihtelevat;

3) runsas glissandojen käyttö; kun Mahler tyytyy vain hienovaraisiin vihjailuihin em. adagio-teeman jousien glissandossa, Villa-Lobos käyttää tätä tyylikeinoa suorastaan tuhlailevasti. Sinänsä glissandojen käyttö jousilla ja puhaltimilla ei ollut vasta Villa-Lobosin 30-luvun tyylikauden tyypillinen piirre vaan jo varhaisissa viulusonaateissa sitä esiintyy - samoin Choroksissa erityisesti vaskipuhaltimilla rajuna purkauksenomaisena efektinä. Tässä glissandojen funktio on selvä: sentimentaalisuuden lisääminen;

4) fermaattitauot rakenteellisesti merkityksettömissä kohdissa; kyseessä on mielivaltaisten hengähdysten luominen eli juuri sävelten ominaispainon liioittelu, joka sai Dahlhausin tuomitsemaan Tshaikovskinkin kitschiksi;

5) melodian tonaalinen rakenne on täysin vapaasti moduloiva eikä sävellajien esiintymisjärjestyksellä ole mitään temaattisesti pakottavaa suuntaa, vaan ne syntyvät kuin improvisoiden. Sikäli kuin tällaista improvisoivaa asenetta pitää 
esteettisesti alempiarvoisena menettelynă ankaran loogiseen suunnitteluun verrattuna, tămäkin on jo riittävă syy banaalisuuden esiintymiseen;

6) melodian intervallirakenne: yleislinja on vapaasti aaltoileva melodia teeman ambitus on yli neljă oktaavia. Tyypillinen piirre on kuitenkin se, ettă milloinkaan teemassa ei ole kahta yli terssin laajuista intervallihyppyă samaan suuntaan, ja että yleensä kaikki hyppyjen luomat aukot musiikillisessa jatkumossa tăytetăăn vălittơmästi. Glissandojen funktio liittyy puolestaan ekspressiivisten intervallihyppyjen, sekstien ja septimien (kohoavien) korostamiseen.

Teema synnyttăă ylipăătăăn vaikutelman ărimmäisen pehmeăsti virtaavasta melodisesta liikkeestă, jossa ei ole mităän erityisen karakteristisia motiiveja, vaan kyseessä on kuin jatkuva ylimeno. Sanalla sanoen tässä teemassa ei ole sitä motiivista painavuutta ja karakteristiikkaa, mită esim. sinfonisen runoelman teemalta odotettaisiin. Teeman vastaanottaminen ei näin ollen edellytä mitään erityisiă intellektuaalisia ponnistuksia kuulijalta, eikă siină ole mităän liian ärsyttäviă tai liian karakteristisia motiiveja, vaan se tuudittaa kuulijan helppoon nautintoon.

Voidaan todella kysyă, mistă năkökulmasta tarkasteltuna nămä kaikki elementit eivăt luo vaikutelmaa triviaalisuudesta ja banaalisuudesta. Minkă lähestymistavan kannalta Bachianas brasileiras nro 2:n ensiosan pääteema on esteettisessä mielessä arvioitava? Adhemar Nobrega toteaa ensinnäkin saksofonin sointiväristä ja tämä soittimen valinnasta: "Se ei voisi olla onnistuneempi. Sekoittuneelta sointiväriltään, joka ei ole metallinen eikä klarinettimainen, pehmeältä ja öljyiseltä aaaneltään saksofonilla on poikkeukselliset edellytykset ilmaista sitä luonnetta, jonka säveltäjä sisällytti tăhän melodiaansa." (Nobrega 1971, 39). Toisin sanoen, sen sijaan että arvioisimme em. "teeman" musiikillisia piirteită yksinomaan länsimaisen kontekstin kannalta, niitä on tarkasteltava myös Villa-Lobosin omassa universumissa, hänen latinalaisamerikkalaisen taustansa suhteen.

Bachianas nro 2:n ensimmäisen osan alaviite antaa kuitenkin vihjeen "siitä luonteesta", jota teeman tuli kuvata: $O$ Canto do capadocio . Ricordin partituuriin tämä otsake on käännetty Maamiehen lauluksi (The Song of the Countryman), mutta Villa-Lobos itse nimittää capadociota eräänlaiseksi malandro brasileiroksi ts. brasilialaiseksi tyhjäntoimittajaksi. Nobrega selostaa käsitteen sisältöä vielä tarkemmin käyttäen siitä synonyymejä charalatao (huijari), parlapatao (lörpöttelijä) ja trapaceiro (petkuttaja). Kyseessä on siis nimenomaan brasilialainen olento, jota Nobrega kuvaa urbaaniksi ihmistyypiksi, henkilöksi jonka moraaliset kvaliteetit ovat alhaiset, mutta jolla on lahjoja erityisesti musiikkiin; tämä ilmenee hänen kyvyssään soittaa kitaraa ja laulaa modinhoja. Villa-Lobos kyllä tunsi omasta kokemuksestaan tämän hieman epämääräisen boheemin ihmistyypin sen kaikissa ilmenemismuodoissaan: "sentimentaalisena ja dramaattisena, lyyrisenä, pateettisena ja traagisena". (ibid. 38).

Bachianas nro 2:n ensiosan pääteeman melodiset motiivit ovat eräänlaisia modinhismoja, katkelmia modinhojen intervallirepertoaarista. Melodisen linjan hajamielisenä vaelteleva hahmo, kiinteän temaattisen substanssin puuttuminen, sensuelli pehmeys jne. - kaikki ovat musiikillisia ominaisuuksia, jotka kuvaavat 
oivallisesti juuri sitä, mită niiden on tarkoituskin kuvata: capadociota. Olisi tietenkin naiivia sekoittaa Villa-Lobosia itseään tähän enemmän tai vähemmän fiktiiviseen henkilöön. Vaikka Balzac kuvaa romaaneissaan moraalittomia ja paheellisia henkilöitä, ei tästä voi päätellä, että hän itse olisi moraaliton ja paheellinen. Kertomuksen subjekti ei ole kerronnan subjekti yhtä vähän musiikissa kuin kirjallisuudessakaan. Näin ollen jos Villa-Lobos käyttää musiikillisesti triviaaleja ja banaaleja elemettejä, hän tekee sen harkitusti - ja saattaa olla että näissä capadocion laulun ylenmäärin vakuuttamaan pyrkivissä sekvenssitoistoissa on hiven ironiaakin - samaa jolla Wagner kuvasi Beckmesseriään tahallisen kömpelöin melodisin kuluin ja toistuvin sekvenssein. Se mitä Mario Pedrosa totesi artikkelissaan Villa-Lobosista Revue Musicalelle 1929 sopii tähän yhteyteen erinomaisesti:

Muuan ranskalainen runoilija sanoi Villa-Lobosin musiikista, ettei hän voinut sietää sitä, koska hän ei pitänyt brutaalisuudesta. Mutta voiko vaatia, että kaikki säveltäisivät Debussyn hienostuneisuudella. --- Innoitus on yhtä jalo ilmaistessaan pehmeyttä ja hienoutta kuin väkivaltaa ja viileyttä. Maku ei ole runouden lähtökohta, se tulee jälkeen päin. --- Toisin sanoen: jollei ota huomioon Brasiliaa, ei voi ymmärtää Villa-Lobosia. Sellaisen taiteilijan kuin Villa-Lobosin taide ei voi olla hienoa eikä erikoista; sen on oltava sitä, mitä se on: villiä ja rajua, sensuellia ja sentimentaalista, sekavaa ja täyttä. Hänessä on myrskypilven täydellistä vilpittömyyttä ja aitoutta. (Pedrosa 1929, 23).

Toisin sanoen triviaalit musiikilliset ainekset ovat Bachianaseissa läsnä siksi, että musiikillinen sisältö ja estetiikka niin vaativat. Luova ihminen on vilpittömyydessään oikeassa, käyttämästään materaalista riippumatta.

\section{Lähteet}

Adorno, Theodor

1958 Philosophien der Neuen Musik. Frankfurt am Main: Europäịsche Verlaganstalt.

Cameu, Helza

i.v. "Heitor Villa-Lobos", portugalinkielinen käsikirjoitus.

Dahlhaus, Carl

1967 "Trivialmusik und ästetisches Urteil" teoksessa Studien zur Trivialmusik des 19. Jahrhunderts. hrsgg. von Carl Dahlhaus. Regensburg: Gustav Bosse Verlag.

Freire, Gilberto

1975 O Brasileiro entre os outros hisponos: afinidades, contrastes e possiveis futuros nas suas interrelacoes. Livraria José Olympio Editora. Rio de

Kneif, Tibor Janeiro.

1967 "Das triviale Bewusstsein in der Musik", teoksessa Studien zur Trivialmusik des 19. Jahrhunderts C. Dahlhaus (hrsgg.). Regensburg: Gustav Bosse Verlag.

Nobrega, Adhemar

1971 As Bachianas Brasileiras Villa-Lobos. Rio de Janeiro: MEC/Museu VillaLobos. 
Orrego-Salas, Juan

1966 "Heitor Villa-Lobos. Figura, obra y estilo", Boletin Interamericano de Musica, numero 52. s. 3-37.

Pedrosa, Mario

1929 "Villa-Lobos et son peuple.Le point de vue brésilien". La Revue

Samuel, Claude Musicale, no. 10, tome IV, s. 23-28.

1962 Panorama de l'Art musical contemporain. Paris: Editions Gallimard. Schönberg, Arnold

1975 Style and Idea. Selected Writings. Edited by Leonard Stein. London: Faber \& Faber.

Stuckenschmidt, Heinrich

1976 Die Musik eines halben Jahrhunderts. 1925-1975. Essay und Kritik. München, Zürich: R. Piper \& Co. Verlag.

\section{Summary}

\section{Bachianas Brasileiras and the problem of national neo-classicism}

The most important of the works of the Brazilian composer Heitor Villa-Lobos (1887-1959) in the 1930's, Bachianas Brasileiras, differs considerably in its style and content from his main work in the twenties, the Choros Suite. The change of style in these and in Villa-Lobos's whole output also reflects a cultural change in Brazil from an agrarian society to an industrialized and urban one. In the music of the Choros we find the pastoral atmosphere of gardens and serenades while in Villa-Lobos's later works one can imagine a cosmopolitan asphalt Rio.

The roots of the Bachianas are deep in the Brazilian culture, and they represent an exaggerated and over-heated nationalism; in the most sophisticated of them one can sense a feeling of universalism and greatness. In the Bachianas, Villa-Lobos goes back to a Brazilian "time" that alludes to the timelessness, archaism, and slowness of the Lévi-Straussian "cold society". The Schoenbergian "developing variation", a typically European invention, is strange to them.

The first movement of the second Bachianas gives rise to a discussion on the problem of "banality". The movements of the composition are unconnected, their only unifying factor being the use of exotic instruments. This particular composition where the saxophone dominates could be described with words like sentimental, empty pathos, tasteless, trivial, false, and pretentious, in other words "kitsch".

When examining the main theme of the first movement of Bachianas Brasileiras nr. 2, a Western listener may find such banalities as (1) poor timbre, especially the use of a saxophone which makes the theme naked and sensual; (2) a simple theme that consists of a series of endless sequences, as connected to each other as a potpourri; (3) an abundant use of glissandi in order to increase sentimentality; (4) sustained pauses at meaningless points where the specific weight of tones is over-emphasized; (5) the poor tonal structure in the melody, where the modulations from one key to another do not take place in logical order but in an improvisational manner; (6) an intervallic structure in the melody that has a wave-like contour and an ambitus range of more than four octaves. The 
theme gives an impression of smoothly flowing melodic movement, whilst the melody does not demand any intellectual effort, it lulls a listener into easy pleasure.

But instead of evaluating the musical features of the "theme" merely in a Western context, they have to be examined in Villa-Lobos's own Latin-American context. A foot-note for Bachianas Brasileiras nr. 2 is $O$ canto do capadocio. Villa-Lobos conceives a "capadocio" as a kind of Brazilian idler, an urban type of man whose moral qualities are low but one who has a talent especially for music: this appears in his ability to play the guitar and to sing modinjos. Thus an absent-mindedly wandering melodic contour, the lack of fixed thematical substance, sensual smoothness etc. are all excellent musical characteristics of a capadocio. Consequently, if Villa-Lobos makes use of musical elements that are trivial and banal in nature, he does it deliberately. Trivial musical components are present in the Bachianas for the reason that this is demanded by the aesthetics and musical content of the work. 